Research Article

\title{
Pharmacokinetic Characterisation and Comparison of Bioavailability of Intranasal Fentanyl, Transmucosal, and Intravenous Administration through a Three-Way Crossover Study in 24 Healthy Volunteers
}

\author{
S. Nardi-Hiebl $\mathbb{D},{ }^{1}$ J. W. Ndieyira $\mathbb{D}^{2},{ }^{2}$ Y. Al Enzi, ${ }^{3}$ W. Al Akkad $\mathbb{D},{ }^{4}$ T. Koch, ${ }^{1}$ G. Geldner, ${ }^{5}$ \\ C. Reyher, ${ }^{6}$ and L. H. J. Eberhart ${ }^{1}$ \\ ${ }^{1}$ Department of Anaesthesia and Intensive Care, University Hospital Marburg, Marburg, Germany \\ ${ }^{2}$ Division of Medicine, University College London, London, UK \\ ${ }^{3}$ Department of Mathematics and Natural Science, Gulf University of Science and Technology, Mubarak Al-Abdullah, Kuwait \\ ${ }^{4}$ Royal Free London Hospital, University College London, London, UK \\ ${ }^{5}$ Department of Anaesthesiology Intensive Care Medicine Emergency Medicine and Pain Therapy, \\ RKH Kliniken-Hospital Ludwigsburg, Ludwigsburg, Germany \\ ${ }^{6}$ Department of Anaesthesiology Intensive Care Medicine Emergency Medicine and Pain Therapy, \\ Klinikum Kassel GmbH, Kassel, Germany
}

Correspondence should be addressed to S. Nardi-Hiebl; stefan.nardi-hiebl@staff.uni-marburg.de

Received 4 October 2021; Revised 25 October 2021; Accepted 16 November 2021; Published 29 November 2021

Academic Editor: Giustino Varrassi

Copyright $(2021$ S. Nardi-Hiebl et al. This is an open access article distributed under the Creative Commons Attribution License, which permits unrestricted use, distribution, and reproduction in any medium, provided the original work is properly cited.

Background. For more than 60 years, the synthetic opioid fentanyl has been widely used in anaesthesia and analgesia. While the intravenous formulation is primarily used for general anaesthesia and intensive care settings, the drug's high lipophilic properties also allow various noninvasive routes of administration. Published data suggest that intranasal administration is also attractive for use as intranasal patient-controlled analgesia (PCA). A newly developed intranasal fentanyl formulation containing $47 \mu \mathrm{g}$ fentanyl, intravenous fentanyl, and oral transmucosal fentanyl citrate were characterised, and bioavailability was compared to assess the suitability of the intranasal formulation for an intranasal PCA product. Methods. 27 healthy volunteers were enrolled in a single-centre, open-label, randomised (order of treatments), single-dose study in a three-period crossover design. The pharmacokinetics of one intranasal puff of fentanyl formulation $(47 \mu \mathrm{g}, 140 \mathrm{~mL}$ per puff), one short intravenous infusion of $50 \mu \mathrm{g}$ fentanyl, and one lozenge with an integrated applicator ( $200 \mu \mathrm{g}$ fentanyl) were studied, and bioavailability was calculated. Blood samples were collected over 12 hours, and plasma concentrations of fentanyl were determined by HPLC with MS/MS detection. Results. 24 volunteers completed the study. The geometric mean of $\mathrm{AUC}_{0 \text {-tlast }}$ was the highest with oral transmucosal administration $(1106 \mathrm{~h} * \mathrm{pg} / \mathrm{ml}, \mathrm{CV} \%=32.86)$, followed by intravenous $(672 \mathrm{~h} * \mathrm{pg} / \mathrm{ml}, \mathrm{CV} \%=32.18)$ and intranasal administration $(515 \mathrm{~h} * \mathrm{pg} / \mathrm{ml}, \mathrm{CV} \%=30.10)$. $C_{\max }$ was $886 \mathrm{pg} / \mathrm{ml}(\mathrm{CV} \%=59.38)$ for intravenous, $338 \mathrm{pg} / \mathrm{ml}(\mathrm{CV} \%=45.61)$ for intranasal, and $310 \mathrm{pg} / \mathrm{ml}(\mathrm{CV} \%=29.58)$ for oral transmucosal administration. $t_{\max }$ was shortest for intravenous administration $(0.06 \mathrm{~h}, \mathrm{SD}=0.056)$, followed by intranasal $(0.21 \mathrm{~h}, \mathrm{SD}=0.078)$ and oral transmucosal administration $(1.20 \mathrm{~h}, \mathrm{SD}=0.763) . \mathrm{Dose}-$ adjusted absolute bioavailability was determined to be $74.70 \%$ for the intranasal formulation and $41.25 \%$ for the oral transmucosal product. In total, 38 adverse events (AEs) occurred. Fourteen AEs were potentially related to the investigational items. No serious AE occurred. Conclusion. Pharmacokinetic parameters and bioavailability of the investigated intranasal fentanyl indicated suitability for its intended use as an intranasal PCA option. 


\section{Introduction}

Fentanyl has been used in anaesthesiology and analgesia for almost 60 years. First synthesised by Paul Janssen in the 1960s, it was introduced in anaesthesia and intensive care medicine as the first high potent $\mu$-receptor agonist with an analgesic potency approximately 100 times higher than morphine [1]. Due to its high lipophilic properties, fentanyl is rapidly distributed and thus offers a relative short-lived analgesic effect of around 30 to 60 minutes. Through multiple or continuous administrations, it can accumulate over time [2]. Either fentanyl base or citrate salt is used for pharmaceutical formulations, whereby the base is virtually water-insoluble. The generally accepted explanation for the metabolisation of fentanyl is through $\mathrm{N}$-dealkylation to norfentanyl by the cytochrome P450 (CYP) 3A4 [3-5], whereby none of the metabolites are considered to be pharmacologically active in a relevant manner [6]. It has been suggested that other unknown metabolic routes play an important role [7]. As a potent opioid, it possesses all the opioid-inherent adverse effects: nausea, vomiting, urinary retention, and pruritus, as well as potential respiratory depression as the most severe consequence [8].

Pharmacological developments over the last 20 years have led to new formulations and drug delivery technologies allowing the noninvasive administration of fentanyl. Such products offer individually adjusted titration and duration of action for a defined episode with a quick onset intended to treat chronic and acute pain states [9-12]. The intravenous formulation is exclusively used in anaesthesia and intensive care as high peak concentrations rapidly lead to acute respiratory depression. On the opposite end of the spectrum, transdermal delivery systems provide stable plasma concentrations with a slow onset qualifying such devices to treat chronic pain. Oral transmucosal and intranasal formulations are commonly utilised for breakthrough pain management for patients on chronic opioid intake. No intranasal delivery systems have been available for fentanyl to be used for opioid-naive patients. Due to the potential issues concerning misuse and abuse of fentanyl, dose control and patient authentication are mandatory safety features.

The intranasal administration route provides various benefits such as ease of use and noninvasiveness. As the nasal cavity comprises a large surface and the turbinate structures support the exposure of the mucosal surface and the inhaled air, absorption of drug compounds is rapid, and the wellperfused epithelial membrane further supports this effect. In addition, small lipophilic compounds such as fentanyl are usually well absorbed from mucosal surfaces, and as such, the onset is often clinically comparable with intravenous injection [13]. Intranasal administration has an added benefit in improving bioavailability by avoiding the enterohepatic first-pass effect since venous outflow of nasal mucosa directly enters systemic circulation [14]. Previous studies with intranasal fentanyl have reported high values for bioavailability, a shorter period to reach maximum concentrations, and faster pain relief compared with other routes of noninvasive administrations [15-18].
Intranasal administration of fentanyl has been systematically studied for use in postoperative pain management, also in the context of intravenous patient-controlled analgesia (i.v. PCA). Patients receiving i.v. PCA report higher satisfaction and better pain control than patients receiving non-patient-controlled analgesia [19]; however, utilisation might not match the necessity to provide the best patient care [20]. One reason for underutilisation is the complexity around i.v. PCA $[21,22]$.

Over the last years, the community has seen two interesting technologies for postoperative pain management: a disposable electronic transdermal system (IONSYS ${ }^{\circledR}$, The Medicines Company, Parsippany/New Jersey, USA) [10] and a dispenser for sublingual tablets in combination with sufentanil-containing bioadhesive nanotablets (Zalviso ${ }^{\circledR}$, Grünenthal GmbH, Aachen, Germany) [23]. These devices offered noninvasive drug delivery without the need for a catheter, consequently a streamlined process and advantages in postoperative mobilisation. However, both products were not commercially viable.

Current development focuses on intranasal PCA as an effective alternative to i.v. PCA while offering the benefits of noninvasive administration [24, 25] with similar satisfaction to i.v. PCA [26]. Although first reported more than 30 years ago, there is no commercial PCA product available incorporating the advantages of intranasal fentanyl for postoperative pain management. The recently developed technical concept for intranasal administration incorporates features for safe postoperative pain management and thus might overcome the challenges previously faced [27].

As part of this development, the characterisation of fentanyl absorption and bioavailability for an intranasal fentanyl formulation and two other fentanyl preparations with different routes of administration are hereby presented. The objective of this study was to investigate and compare the bioavailability of the new formulation containing $47 \mu \mathrm{g}$ fentanyl ( $74 \mu \mathrm{g}$ fentanyl citrate) and $0.1 \%$ sodium hyaluronate (added for better tolerability) in $140 \mu \mathrm{l}$ per spray puff with intravenous and oral transmucosal administration through a three-way crossover study in 24 healthy subjects.

\section{Materials and Methods}

After the Institutional Ethics Committee approval, the study was registered with the European Union Drug Regulating Authorities Clinical Trials Database (No. 003034-17) and subsequently conducted per protocol, the principles of the Declaration of Helsinki, ICH-GCP guidelines, and the requirements of the German Drug Law [28, 29].

2.1. Volunteer Selection. Twenty-seven healthy nonsmoking men and women aged between 18 and 55 years with a body mass index between 18 and $27 \mathrm{~kg} / \mathrm{m}^{2}$ were recruited, thereof 15 women and 12 men. All volunteers provided written informed consent. All study participants were in good health. Screening at commencement and with the conclusion of the study was conducted according to protocol. Screening included the medical history, physical 
examination, clinical laboratory tests, 12-lead ECG, pregnancy testing for women, and alcohol and drug screening. No clinically relevant deviations from standard results or laboratory findings were found. The physical examination, clinical laboratory tests, and ECG were repeated at the end of the study. At the beginning of each study period, vital parameters were assessed, and before administration, one and 12 hours after administration, safety laboratory parameters (SGPT/ALAT, SGOT/ASAT, $\gamma$-GT) were determined. Tolerability monitoring included periodic measurement of vital signs and recording of adverse events.

2.2. Study Design. This study was performed at a phase I unit as an open-label, randomised (order of treatments), singledose study in a three-period crossover design within a timeframe of four weeks with at least a three-day wash-out period between each period.

The investigational items were administered either as a single intranasal puff of the new fentanyl formulation ( $47 \mu \mathrm{g}$ fentanyl, $140 \mu \mathrm{L}$ per puff) (INTRANASAL), a short intravenous infusion of $50 \mu \mathrm{g}$ fentanyl $(1 \mathrm{~mL}$ ) (INTRAVENOUS), or one lozenge with an integrated applicator (oral transmucosal fentanyl citrate-200 $\mu \mathrm{g}$ fentanyl) (TRANSMUCOSAL).

To reduce the risk of pronounced respiratory depression or effects of unreported drug dependence before this study, naltrexone was coadministered at all three time points. The volunteers received orally $25 \mathrm{mg}$ naltrexone hydrochloride the evening before study day, followed by observation of one hour for withdrawal symptoms. Further, $50 \mathrm{mg}$ naltrexone hydrochloride per os was administered three hours before administration of fentanyl. While volunteers resided in the study confinement, intake of food and beverages was standardised. All volunteers fastened at least 10 hours before administration of any investigational item. Only drinking water was allowed up to four hours before administration except for $150 \mathrm{~mL}$ water for the intake of naloxone three hours before administration. On the study day, the volunteers received standardised meals at three, six, and 12 hours after administration.

2.3. Sampling and Data Collection. Before the commencement of the first administration, each volunteer was randomly assigned to one of the six sequences (full permutation).

Before receiving intranasal administration, the respective volunteer was asked to clean up the nose by carefully blowing to avoid malabsorption due to mucous residues. Any sign of rhinitis, nose bleeding, blocked nose, or other specifics that could impair the absorption could lead to exclusion for intranasal administration. After administering the spray puff, the volunteer was instructed to avoid any manipulation on the nose for one hour. Volunteers prepared for intravenous administration received the study medication diluted in $10 \mathrm{~mL}$ of $0.9 \%$ sodium chloride as a short infusion facilitated by a syringe pump for 2 minutes. In the case of the lozenge, the oral cavity of the volunteer was assessed for any signs of mucous lesions, inflammations, specific or global oral pain incidents, and other specifics, which may result in the exclusion. Within five to 15 minutes before administering, the volunteer was requested to clean and moisten the oral cavity by taking a sip of water. For administration purposes, the volunteer moved the lozenge rotating along the cheeks for up to 15 minutes until the entire drug-containing matrix was dissolved.

According to the investigational item, blood sampling took place using an intravenous cannula and was performed in an adopted schedule. For nasal administration, samples were taken before and $3 \mathrm{~min}, 6 \mathrm{~min}, 9 \mathrm{~min}, 12 \mathrm{~min}, 15 \mathrm{~min}$, $20 \mathrm{~min}, 25 \mathrm{~min}, 30 \mathrm{~min}, 45 \mathrm{~min}, 60 \mathrm{~min}, 80 \mathrm{~min}, 100 \mathrm{~min}$, $120 \mathrm{~min}, 2.5 \mathrm{~h}, 3 \mathrm{~h}, 4 \mathrm{~h}, 5 \mathrm{~h}, 6 \mathrm{~h}, 8 \mathrm{~h}$, and $12 \mathrm{~h}$ (21 samples) after administration, for intravenous administration, samples were taken prior to and $2 \mathrm{~min}$ (end of infusion), $5 \mathrm{~min}$, $8 \mathrm{~min}, 11 \mathrm{~min}, 15 \mathrm{~min}, 20 \mathrm{~min}, 30 \mathrm{~min}, 45 \mathrm{~min}, 60 \mathrm{~min}$, $80 \mathrm{~min}, 100 \mathrm{~min}, 120 \mathrm{~min}, 2.5 \mathrm{~h}, 3 \mathrm{~h}, 4 \mathrm{~h}, 5 \mathrm{~h}, 6 \mathrm{~h}, 8 \mathrm{~h}$, and $12 \mathrm{~h}$ (20 samples) after administration, and for oral transmucosal administration, samples were taken prior to and $5 \mathrm{~min}$, $10 \mathrm{~min}, 15 \mathrm{~min}$ (the latest at the end of sucking), $20 \mathrm{~min}$, $25 \mathrm{~min}, 30 \mathrm{~min}, 45 \mathrm{~min}, 60 \mathrm{~min}, 80 \mathrm{~min}, 100 \mathrm{~min}, 120 \mathrm{~min}$, $2.5 \mathrm{~h}, 3 \mathrm{~h}, 3.5 \mathrm{~h}, 4 \mathrm{~h}, 5 \mathrm{~h}, 6 \mathrm{~h}, 8 \mathrm{~h}$, and $12 \mathrm{~h}$ (20 samples) after administration.

The blood samples were taken using heparinised $7.5 \mathrm{~mL}$ tubes (Monovette, Sarstedt) and were centrifuged within 30 minutes of withdrawal $\left(2000 \mathrm{~g}, 10\right.$ minutes, $\left.4^{\circ} \mathrm{C}\right)$. The supernatant plasma was frozen latest 60 minutes after sampling at $-20^{\circ} \mathrm{C}$ and stored in a frozen state until called for analysis.

2.4. Analytical Procedures. Fentanyl analysis was based on a solid-phase extraction from plasma followed by its determination using high-performance liquid chromatography (HPLC) in which the HPLC method was coupled to MS/MS detector (Agilent Technologies, MicroMass) with analytical columns (Polaris C18-A, $5 \mu \mathrm{m}, 100 \times 3.0 \mathrm{~mm}$ ).

To extract fentanyl, $500 \mu \mathrm{L}$ plasma of each sample was pipetted per well into a 96-well plate, and $500 \mu \mathrm{L} 2.5 \%$ acetic acid (containing the IS) was added. The well plate was shaken for 5 minutes at $1000 \mathrm{rpm}$. The samples were transferred onto a preconditioned (with $400 \mu \mathrm{L}$ methanol without vacuum and $400 \mu \mathrm{L} 0.1 \%$ acetic acid) MP1 SPEC plate. The samples were passed through the plate by low vacuum. The plate was washed with $400 \mu \mathrm{L} 0.1 \%$ acetic acid followed by $200 \mu \mathrm{L}$ methanol. Subsequently, the plate was dried by high vacuum for 10 minutes. The plate was then eluted four times with $100 \mu \mathrm{L}$ each of methanol/ammonia solution, and $10 \mu \mathrm{L}$ was injected. To determine the final fentanyl concentration, the experimental conditions consisted of $2 \mathrm{mM}$ ammonium acetate buffer at $\mathrm{pH} 4.5$ (Solvent A) and $0.1 \%$ formic acid in methanol (Solvent B) with a defined ratio of Solvent B/Solvent A fixed at $90 \%$ to $10 \%$ and mixed by HPLC pump during run with a flow rate of $0.2 \mathrm{~mL} /$ min and 5 min run time.

The peak area of transitions of $\mathrm{m} / \mathrm{z} \quad 337.2 \Rightarrow 188.3$ was monitored during multiple reaction monitoring against $\mathrm{m} / \mathrm{z}$ $342.2 \Rightarrow 188.3$ for the internal standard fentanyl-d5. Three transitions were attached in the MS method to reduce crosstalk 
from the internal standard and reverse. The calculation of analyte concentration was obtained from the response of peak area of the analyte to the peak area of the internal standard, using a quadratic fit with $1 /$ concentration weighting.

Before validating the plasma fentanyl concentration, first, the fentanyl standard solutions to be used for the calibration curves were prepared in blank plasma. $10 \mathrm{pg} / \mathrm{mL}$ fentanyl addition was set as the lower limit of quantitation, and the calibration curves were linear over the entire measurement range of 10 to $1000 \mathrm{pg} / \mathrm{mL}$ so that the sample measurements were effectively controlled by the calibration curves. For each concentration, the accuracy was characterised between $\pm 13.1 \%$ (LLQC) and $\pm 8.2 \%$ (HQC) with precision between $\pm 8.1 \%$ (HQC) and $\pm 11.5 \%$ (MQC), respectively, thus confirming that the resulting values were within acceptance criteria. Intra- and inter-day variations of quality control samples covering the intended concentration range demonstrated that accuracy and precision were well within the established acceptance criteria. For accuracy, the mean value was within $15 \%$ of the actual value, and for precision, the value at each concentration level did not exceed $15 \%$ of the coefficient of variation (CV). The standard approach of the US-FDA Guidance for Industry on Bioanalytical Method Validation was followed.

2.5. Pharmacokinetic Parameters. Pharmacokinetic parameters were determined model-independently for each treatment phase, and characteristics were derived directly from measured concentrations; noncompartmental analysis (NCA) was utilised. Actual sampling times were considered for evaluation.

The area under the concentration versus time curve from administration time to the last measurement time point with a concentration value above the lower limit of quantification $\left(\mathrm{AUC}_{0 \text {-tlast }}\right)$ was calculated using the linear trapezoidal rule up to $C_{\max }$ and subsequently the log trapezoidal rule for the remainder of the curve. $\mathrm{AUC}_{0-\infty}$ was calculated as the sum of $\mathrm{AUC}_{0 \text {-tlast }}$ and $\mathrm{AUC}_{\text {expol}}$, whereby $\mathrm{AUC}_{\text {expol }}$ was determined by the concentration at the last time quantifiable point $\left(\mathrm{C}_{\text {last }}\right)$ divided by the apparent terminal elimination rate constant $\lambda$, calculated by log-linear regression analysis taking into account the baseline-corrected values above zero.

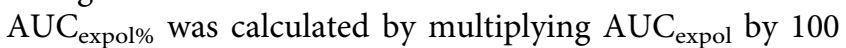
and divided by $\mathrm{AUC}_{0-\infty}$. Terminal half-life $\left(t_{1 / 2}\right)$ was calculated by dividing the natural logarithm of 2 by $\lambda$.

2.6. Statistical Evaluation. Descriptive statistics were presented for all determined pharmacokinetic parameters and adverse events without dose adjustment to present individual characterisation. We utilised the software applications Phoenix WinNonlin (Certara Companies), MedCalc (MedCalc Software), and Microsoft Excel (Microsoft Corporation) for calculations and analysis. Statistical analysis was performed with a significance level of 0.05 . A blinded review of the results and general applicability of the statistical procedure on the study data set, identification of possible outliers, and decision upon exclusion of subjects from analysis or specific calculations were performed.
We conducted a pairwise statistical comparison of $C_{\max }$, $t_{\max }$ and $\mathrm{AUC}_{0 \text {-tlast }}$, whereby we used the two-sided $t$-test for $C_{\max }$ and $\mathrm{AUC}_{0 \text {-tlast }}$ and the Mann-Whitney test for $t_{\max }$. The values for $C_{\max }$ and $\mathrm{AUC} \mathrm{AUC}_{0 \text {-tlast }}$ were found to be normally distributed (D'Agostino-Pearson test). For statistical comparison of bioavailability, we applied dose adjustment to the investigational items. Relative bioavailability was derived by the ratios of geometric means (point estimates). As interval estimates, $90 \%$ confidence intervals (CI) were determined by parametric analysis (two one-sided $t$ tests). While a multiplicative model was applied for all AUC and $\mathrm{C}_{\max }$ analyses, $t_{\max }$ and $t_{1 / 2}$ were analysed by employing an additive model. The factors considered for variance analysis for $\mathrm{AUC}_{0 \text {-tlast, }} \mathrm{AUC}_{0-\infty}$, and $C_{\max }$ values were formulation, period, sequence, and volunteer (sequence). Intra-subject variabilities were estimated, and period, subject, and sequence effects were determined.

We concluded that obtaining data from 27 volunteering individuals was appropriate to meet the study's objective and the financial means allocated. Therefore, we did not calculate the sample size.

2.7. Adverse Events. Any pretreatment signs and symptoms (PTSS) and adverse events (AEs) reported were classified regarding severity and potential relationship with the administration of the investigational items. In the case of an $\mathrm{AE}$, the volunteer was monitored and followed up until satisfactory recovery.

\section{Results and Discussion}

\subsection{Results}

3.1.1. Study Population. 24 of 27 enrolled volunteers completed the study (Table 1). One volunteer dropped out due to vomiting after intake of naltrexone, and another volunteer dropped out due to continuous vomiting after intake of the first investigational item. One further volunteer stated personal reasons for leaving the study after completing the first period.

While data from all 27 volunteers were included in the safety analysis, only the data of the 24 volunteers completing the study were used for pharmacokinetic analysis.

The study was conducted without significant protocol deviation. Even where minor deviations occurred, neither of them were judged as clinically or pharmacokinetically influential and relevant.

3.1.2. Descriptive Statistics. Compared to INTRANASAL, INTRAVENOUS presented a significantly higher geometric mean of Cmax (Tables 2-4, Figure 1). INTRAVENOUS also presented a significantly higher $C_{\max }$ than TRANSMUCOSAL (Table 5), but no significant difference in $C_{\max }$ between INTRANASAL and TRANSMUCOSAL could be determined. In absolute values, INTRAVENOUS exhibited the highest level of $C_{\max }$ with $886 \mathrm{pg} / \mathrm{ml}$ (geometric mean, $\mathrm{SD}=59.38$ ). 
TABLE 1: Characteristics of volunteers completing the study.

\begin{tabular}{lcccc}
\hline & & \multicolumn{2}{c}{$n=24(12$ males, 12 females $)$} & \\
& Age (years) & Height $(\mathrm{cm})$ & Weight $(\mathrm{kg})$ & 70.50 \\
BMI $\left(\mathrm{kg} / \mathrm{m}^{2}\right)$ \\
\hline Median & 32.0 & 173.5 & 72.52 & 24.07 \\
Mean & 33.8 & 173.5 & 11.683 & 23.96 \\
SD & 10.22 & 9.97 & 53.0 & 1.893 \\
Min & 18 & 156 & 101.8 & 19.9 \\
Max & 51 & 194 & & 27.0 \\
\hline
\end{tabular}

TABLE 2: Pharmacokinetic parameters for single administration of INTRANASAL.

\begin{tabular}{|c|c|c|c|c|c|c|c|c|c|c|}
\hline \multicolumn{11}{|c|}{ INTRANASAL (intranasal fentanyl, $140 \mu \mathrm{L}$ per puff, $47 \mu \mathrm{g}$ )-one puff } \\
\hline & $\mathrm{AUC}_{0 \text {-tlast }}$ & $\mathrm{AUC}_{0-\infty}$ & $\mathrm{AUC}_{\text {expol\% }}$ & $C_{\max }$ & $\mathrm{C}_{\text {last }}$ & $t_{\max }$ & $t_{1 / 2}$ & $t_{\text {last }}$ & $\lambda_{z}$ & MRT \\
\hline $\mathrm{N}$ & 24 & 23 & 23 & 24 & 24 & 24 & 23 & 24 & 23 & 23 \\
\hline Unit & $\mathrm{h} * \mathrm{pg} / \mathrm{ml}$ & $\mathrm{h} * \mathrm{pg} / \mathrm{ml}$ & $\%$ & $\mathrm{pg} / \mathrm{ml}$ & $\mathrm{pg} / \mathrm{ml}$ & $\mathrm{h}$ & $\mathrm{h}$ & $\mathrm{h}$ & $1 / \mathrm{h}$ & $\mathrm{h}$ \\
\hline Arith. Mean & & & & & & 0.21 & 12.18 & 10.71 & 0.13898 & 2.92 \\
\hline $\mathrm{SD}$ & & & & & & 0.078 & 9.513 & 2.647 & 0.20596 & 0.789 \\
\hline Min & 296 & 323 & 3.69 & 111 & 10 & 0.10 & 0.71 & 4.00 & 0.02004 & 1.19 \\
\hline Median & 571 & 748 & 23.33 & 370 & 15 & 0.20 & 8.05 & 12.00 & 0.08608 & 3.14 \\
\hline $\operatorname{Max}$ & 846 & 1726 & 63.84 & 595 & 24 & 0.50 & 34.59 & 12.02 & 0.97349 & 4.02 \\
\hline Geom. Mean & 515 & 766 & 25.09 & 338 & 16 & & & & & \\
\hline CV\% < Geom. Mean & 30.10 & 47.25 & 80.05 & 45.61 & 27.16 & & & & & \\
\hline
\end{tabular}

$\mathrm{AUC}_{0 \text {-tlast: }}$ area under the plasma concentration versus time curve from dosing time to the last measurement time point with concentration value above the lower limit of quantitation; $\mathrm{AUC}_{0-\infty}$ : area under the plasma concentration versus time curve from dosing time to the infinite; $\mathrm{AUC}_{\text {expol\%: fraction of the total }}$ AUC due to extrapolated AUC; $C_{\max }$ : maximum concentration in plasma; $\mathrm{C}_{\text {last }}$ : concentration at the last time quantifiable point; $t_{\text {max }}$ : time to reach maximum drug concentration; $t_{1 / 2}$ : terminal half-life; $t_{\text {last }}$ last quantifiable time point; $\lambda_{z}$ : apparent terminal elimination rate constant; MRT: mean residence time; SD: standard deviation; CV\%: coefficient of variation.

TABLE 3: Pharmacokinetic parameters for single administration of INTRAVENOUS.

\begin{tabular}{|c|c|c|c|c|c|c|c|c|c|c|}
\hline \multicolumn{11}{|c|}{ INTRAVENOUS (intravenous infusion, $10 \mathrm{~mL}, 50 \mu \mathrm{g}$ )—one short infusion (administration over 2 minutes) } \\
\hline & $\mathrm{AUC}_{0 \text {-tlast }}$ & $\mathrm{AUC}_{0-\infty}$ & $\mathrm{AUC}_{\text {expol\% }}$ & $C_{\max }$ & $\mathrm{C}_{\text {last }}$ & $t_{\max }$ & $t_{1 / 2}$ & $t_{\text {last }}$ & $\lambda_{z}$ & MRT \\
\hline $\mathrm{n}$ & 24 & 21 & 21 & 24 & 24 & 24 & 21 & 24 & 21 & 21 \\
\hline Unit & $\mathrm{h} * \mathrm{pg} / \mathrm{ml}$ & $\mathrm{h} * \mathrm{pg} / \mathrm{ml}$ & $\%$ & $\mathrm{pg} / \mathrm{ml}$ & $\mathrm{pg} / \mathrm{ml}$ & $\mathrm{h}$ & $\mathrm{h}$ & $\mathrm{h}$ & $1 / \mathrm{h}$ & $\mathrm{h}$ \\
\hline Arith. Mean & & & & & & 0.06 & 23.09 & 11.01 & 0.13205 & 27.13 \\
\hline $\mathrm{SD}$ & & & & & & 0.056 & 39.350 & 2.342 & 0.17853 & 51.293 \\
\hline Min & 291 & 317 & 2.44 & 303 & 11 & 0.03 & 0.93 & 5.00 & 0.00430 & 1.14 \\
\hline Median & 697 & 973 & 21.86 & 938 & 16 & 0.03 & 7.94 & 12.00 & 0.08726 & 7.46 \\
\hline Max & 1230 & 7162 & 84.52 & 2035 & 39 & 0.25 & 161.03 & 12.05 & 0.74557 & 206.88 \\
\hline Geom. Mean & 672 & 1111 & 22.72 & 886 & 18 & & & & & \\
\hline CV\% geom. Mean & 32.18 & 78.41 & 109.82 & 59.38 & 41.12 & & & & & \\
\hline
\end{tabular}

$\mathrm{AUC}_{0 \text {-tlast: }}$ area under the plasma concentration versus time curve from dosing time to the last measurement time point with concentration value above the lower limit of quantitation; $\mathrm{AUC}_{0-\infty}$ : area under the plasma concentration versus time curve from dosing time to the infinite; $\mathrm{AUC}_{\text {expol\%: }}$ fraction of the total AUC due to extrapolated AUC; $C_{\max }$ : maximum concentration in plasma; $\mathrm{C}_{\text {last }}$ : concentration at the last time quantifiable point; $t_{\text {max }}$ : time to reach maximum drug concentration; $t_{1 / 2}:$ terminal half-life; $t_{\text {last }}$ last quantifiable time point; $\lambda_{z}:$ apparent terminal elimination rate constant; MRT: mean residence time; SD: standard deviation; CV\%: coefficient of variation.

TABLE 4: Significance level of comparison of means between routes of administration.

\begin{tabular}{|c|c|c|c|c|}
\hline \multicolumn{5}{|c|}{ Comparison } \\
\hline & & $C_{\max }$ & $t_{\max }$ & $\mathrm{AUC}_{0 \text {-tlast }}$ \\
\hline INTRANASAL & INTRAVENOUS & $p<0.0001$ & $p<0.0001$ & $p<0.0023$ \\
\hline INTRANASAL & TRANSMUCOSAL & $p<0.1825$ & $p<0.0001$ & $p<0.0001$ \\
\hline TRANSMUCOSAL & INTRAVENOUS & $p<0.0001$ & $p<0.0001$ & $p<0.0001$ \\
\hline
\end{tabular}

Systemic exposure $\left(\mathrm{AUC}_{0 \text {-tlast }}\right)$ between INTRANASAL and INTRAVENOUS was significantly distinct, and the comparison of the $\mathrm{AUC}_{0 \text {-tlast value of TRANSMUCOSAL }}$ with INTRANSAL and INTRAVENOUS indicated a significant difference, too.

The time to reach maximum drug concentration in plasma $\left(t_{\max }\right)$ was significantly different between the compared items. INTRAVENOUS and INTRANASAL lead to a comparatively short $t_{\max }(0.06 \mathrm{~h}$ and $0.21 \mathrm{~h})$; TRANSMUCOSAL exhibited a considerably higher $t_{\max }$ value $(1.2 \mathrm{~h}, \mathrm{SD}=0.763)$ (Figure 2$)$.

The mean curve of INTRANASAL showed a steep and fast increase within the first minutes after administration peaking after 12 minutes with a constant decrease over time 


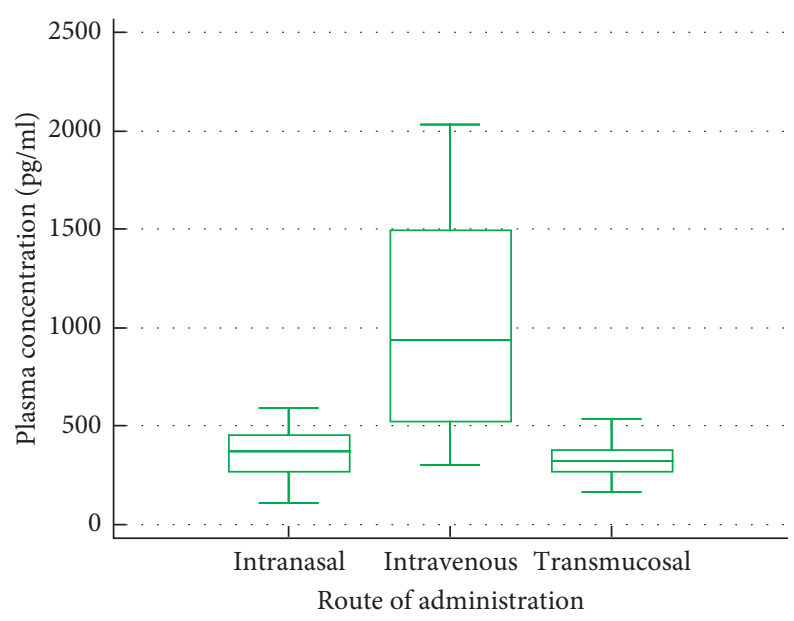

FIgURE 1: Box and whisker plot of $C_{\max }$ values.

TABLE 5: Pharmacokinetic parameters for single administration of TRANSMUCOSAL.

TRANSMUCOSAL (oral transmucosal fentanyl citrate, 1 lozenge, $200 \mu \mathrm{g}$ )—one lozenge (administration over 15 minutes)

\begin{tabular}{|c|c|c|c|c|c|c|c|c|c|c|}
\hline & $\mathrm{AUC}_{0 \text {-tlast }}$ & $\mathrm{AUC}_{0-\infty}$ & $\mathrm{AUC}_{\text {expol\% }}$ & $C_{\max }$ & $\mathrm{C}_{\text {last }}$ & $t_{\max }$ & $t_{1 / 2}$ & $t_{\text {last }}$ & $\lambda_{z}$ & MRT \\
\hline $\mathrm{N}$ & 24 & 21 & 21 & 24 & 24 & 24 & 21 & 24 & 21 & 21 \\
\hline Unit & $\mathrm{h} * \mathrm{pg} / \mathrm{ml}$ & $\mathrm{h} * \mathrm{pg} / \mathrm{ml}$ & $\%$ & $\mathrm{pg} / \mathrm{ml}$ & $\mathrm{pg} / \mathrm{ml}$ & $\mathrm{h}$ & $\mathrm{h}$ & $\mathrm{h}$ & $1 / \mathrm{h}$ & $\mathrm{h}$ \\
\hline Arith. Mean & & & & & & 1.20 & 12.09 & 11.76 & 0.10910 & 3.74 \\
\hline SD & & & & & & 0.763 & 16.190 & 1.226 & 0.09975 & 0.567 \\
\hline Min & 434 & 457 & 4.91 & 164 & 11 & 0.42 & 1.35 & 6.00 & 0.00899 & 1.81 \\
\hline Median & 1102 & 1452 & 26.50 & 326 & 37 & 1.04 & 7.86 & 12.00 & 0.08824 & 3.83 \\
\hline Max & 1925 & 7017 & 80.98 & 535 & 77 & 2.52 & 77.09 & 12.05 & 0.51173 & 4.53 \\
\hline Geom. Mean & 1106 & 1605 & 23.89 & 310 & 34 & & & & & \\
\hline CV\% geom. Mean & 32.86 & 61.49 & 64.02 & 29.58 & 47.21 & & & & & \\
\hline
\end{tabular}

$\mathrm{AUC}_{0 \text {-tlast: }}$ area under the plasma concentration versus time curve from dosing time to the last measurement time point with concentration value above the lower limit of quantitation; $\mathrm{AUC}_{0-\infty}$ : area under the plasma concentration versus time curve from dosing time to the infinite; $\mathrm{AUC}_{\text {expol\%: }}$ fraction of the total AUC due to extrapolated AUC; $C_{\max }$ : maximum concentration in plasma; $C_{\text {last }}$ : concentration at the last time quantifiable point; $t_{\max }$ : time to reach maximum drug concentration; $t_{1 / 2}$ : terminal half-life; $t_{\text {last }}$ last quantifiable time point; $\lambda_{z}$ : apparent terminal elimination rate constant; MRT: mean residence time; SD: standard deviation; CV\%: coefficient of variation.

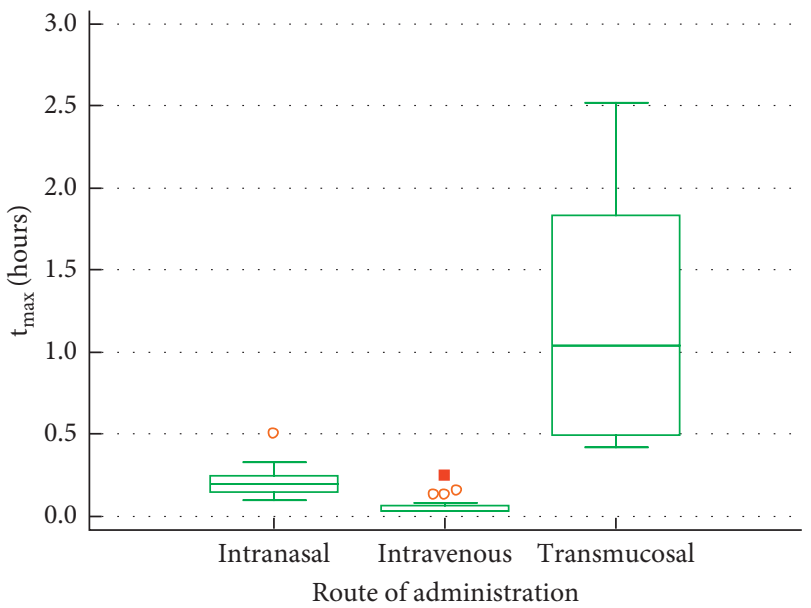

FIgURE 2: Box and whisker plot of $t_{\max }$ values.

(Figure 3). TRANSMUCOSAL depicted a biphasic plasma concentration profile. INTRAVENOUS illustrated peak level at the first time point followed by a continuous decrease.

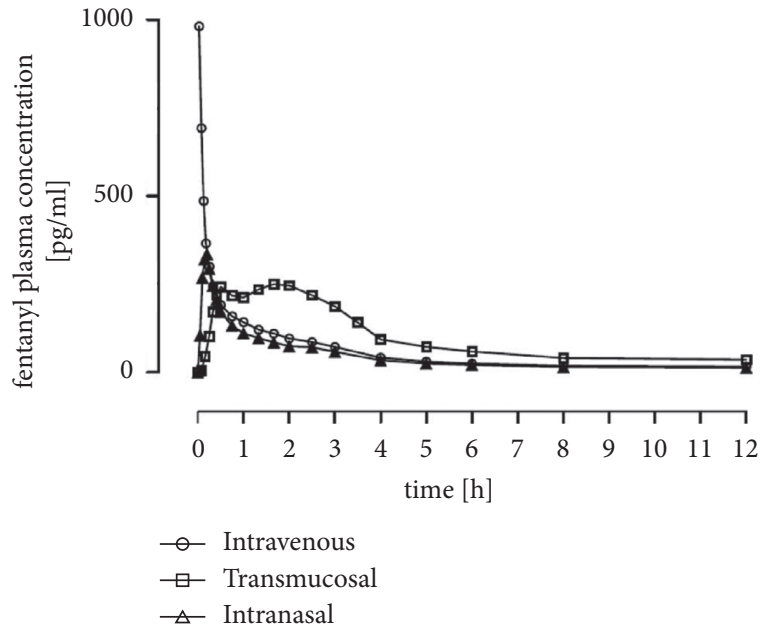

FIGURE 3: Overlay of mean plasma concentration versus time curves of fentanyl of INTRAVENOUS, TRANSMUCOSAL, and INTRANASAL.

3.1.3. Bioavailability Analysis. The values of $\mathrm{AUC}_{0 \text {-tlast }}$ point estimates for INTRANASAL in comparison with the two other investigational items ranged between $45.27 \%$ and 
TABle 6: Parametric point estimates for $\mathrm{AUC}_{0-\text { tlast }}$ after dose adjustment.

\begin{tabular}{lcccccc}
\hline & & \multicolumn{2}{c}{$\mathrm{AUC}_{0 \text {-tlast }}$} & & & \\
\multicolumn{1}{c}{ Comparison } & $\mathrm{PE}(\%)$ & $90 \% \mathrm{CI}(\%)$ & $\mathrm{CV}_{\text {ANOva }}(\%)$ & Power (\%) \\
\hline INTRANASAL & INTRAVENOUS & 74.70 & 69.01 & 80.87 & 16.10 & 99.74 \\
INTRANASAL & TRANSMUCOSAL & 45.27 & 41.64 & 49.23 & 17.00 & 99.54 \\
TRANSMUCOSAL & INTRAVENOUS & 165.01 & 152.83 & 178.15 & 15.60 & 99.83 \\
TRANSMUCOSAL & INTRAVENOUS & 41.25 & 38.21 & 44.54 & 15.60 & 99.83 \\
INTRANASAL & TRANSMUCOSAL & 198.18 & 182.26 & 215.49 & 17.40 & 99.54 \\
\hline
\end{tabular}

${ }^{*}$ Dose adjusted to $50 \mu \mathrm{g}$ fentanyl. ${ }^{* *}$ dose adjusted to $47 \mu \mathrm{g}$ fentanyl.

198.18\%. Absolute bioavailability $\left(\mathrm{F}_{\mathrm{abs}}\right)$ was determined at $74.70 \%$ (90\% CI: $69.01-80.87, \mathrm{CV}_{\mathrm{ANOVA}}: 16.10 \%$, power: 99.74\%) (Table 6).

Comparing INTRANASAL to non-dose-adjusted TRANSMUCOSAL leads to a relative bioavailability $\left(\mathrm{F}_{\text {rel }}\right)$ of $45.27 \%$ (90\% CI: $41.64-49.23, \mathrm{CV}_{\text {ANOVA: }} 17.00 \%$, power: 99.54\%), while adjusting the dose of TRANSMUCOSAL to $47 \mu \mathrm{g}$ resulted in $\mathrm{F}_{\text {rel }}$ of $198.18 \%$ (90\% CI: 182.26-215.49, $\mathrm{CV}_{\text {ANOVA }}: 17.40 \%$, power: $\left.99.54 \%\right)$.

$C_{\max }$ point estimates for dose-adjusted INTRANASAL compared to INTRAVENOUS were $37.22 \%$ (90\% CI: $30.15-45.94, \mathrm{CV}_{\text {ANOVA: }}: 44.50 \%$, power: $51.13 \%$ ), while that for dose-adjusted TRANSMUCOSAL compared to INTRAVENOUS was only $8.78 \%$ (90\% CI: $7.02-10.99, \mathrm{CV}_{\mathrm{A}-}$ NOVA: $45.60 \%$, power: $49.72 \%)$; however, both value calculations exhibited low power (Table 7).

3.1.4. Adverse Events. In total, 17 of the 27 volunteers reported 38 adverse events (AEs) (Table 8). 31 AEs were classified as mild, while 7 AEs were classified as moderate. 14 of the $38 \mathrm{AEs}$ appeared to have a possible relationship with the investigational products. Five AEs occurred after administering naltrexone hydrochloride. For 24 AEs, no causal relationship or classification could be established. None of the AEs were considered severe. All volunteers experiencing AEs recovered without any sequelae.

The five most common reported AEs were nausea (7 $\mathrm{AEs})$, headache (5 AEs), and vomiting (3 AEs). Further AEs reported more than once included tiredness and stomach pain (2 AEs each).

In comparison with INTRAVENOUS and TRANSMUCOSAL, the administration of INTRANASAL resulted in the highest number of drug-related AEs (7 AEs versus 3 AEs versus $4 \mathrm{AEs}$ ). INTRANASAL also exhibited the highest total number of AEs (14 AEs versus 12 AEs versus 6 AEs).

From the list of the five most common reported AEs, headache (2 AEs), vomiting (2 AEs), and tiredness (2 AEs) were the most frequent events for INTRANASAL, nausea ( 4 AEs) for INTRAVENOUS, and headache (2 AEs) and nausea (2 AEs) for TRANSMUCOSAL.

3.2. Discussion. The study enrolled 27 healthy volunteers of both sexes in a monocentric, open-label, sequence randomised approach performed in a three-period changeover design whereby 24 volunteers completed. According to the randomisation plan, one of three investigational products were administered during each period either as a single intranasal spray puff of $140 \mu \mathrm{L}$ containing $47 \mu \mathrm{g}$ fentanyl, one intravenous infusion of $10 \mathrm{~mL}$ sodium chloride containing $50 \mu \mathrm{g}$ fentanyl over two minutes, or one lozenge with an integrated applicator for oral transmucosal absorption containing $200 \mu \mathrm{g}$ fentanyl administered over 15 minutes. To our knowledge, the data presented hereby represent the first publication of direct pharmacokinetic comparison for the three different routes of administration of fentanyl within the same study subjects.

The investigational item INTRAVENOUS was primarily chosen not only for pharmacokinetic but also for safety comparison reasons. The investigational product TRANSMUCOSAL had been selected because it is prescribed for pain episodes of acute pain in cancer patients and thus principally thought to be close to the potential indication of postoperative pain as the target indication for the INTRANASAL product. Therefore, it is anticipated that the comparison of maximum systemic exposure between INTRANASAL and TRANSMUCOSAL would indicate a potential comparable therapeutic effect for acute postoperative pain.

In previous studies, values for bioavailability and $C_{\max }$ for oral transmucosal fentanyl citrate of $50 \%$ and $0.4 \mathrm{ng} / \mathrm{mL}$ (arithmetic mean) were reported [30]. This study observed $41 \%$ and $310 \mathrm{pg} / \mathrm{mL}$ (geometric mean). Values between $55 \%$ and $71 \%$ for bioavailability and $0.36 \mathrm{ng} / \mathrm{mL}$ (median) for $C_{\max }$ were reported for a nasal spray containing $50 \mu \mathrm{g}$ fentanyl per puff [13], while values of $74.71 \%$ and $370 \mathrm{pg} / \mathrm{mL}$ were determined for INTRANASAL. However, one study reported a substantial lower $C_{\max }(180 \mathrm{pg} / \mathrm{mL})$ while administering a slightly higher amount of intranasal fentanyl (54 $\mathrm{g}$ fentanyl per puff) [16]. The most probable explanation for this deviation is the analytical method used in this study, which employed a radioimmunoassay with a $40 \mathrm{pg} / \mathrm{mL}$ LOD to quantify fentanyl concentrations in plasma.

Differences in comparison with other studies [31-33] result from different sampling and observation times, which might not necessarily allow an accurate determination of $t_{1 / 2}$ and subsequently lead to an underestimation of $t_{1 / 2}$ and AUC while overestimating clearance $(\mathrm{Cl})$. As fentanyl distributes rapidly, accurate and close sampling during the first minutes after administration is crucial. This study, therefore, sampled initially in a 3-minute interval for intravenous and intranasal administration up to 15 minutes.

Within the INTRAVENOUS and TRANSMUCOSAL groups, $C_{\max }$ and $t_{\max }$ values, respectively, exhibited comparatively high variations. This is consistent with previous findings that such pharmacokinetic parameters 
TABle 7: Parametric point estimates for $C_{\max }$ after dose adjustment.

\begin{tabular}{|c|c|c|c|c|c|c|}
\hline \multicolumn{7}{|c|}{$C_{\max }$} \\
\hline \multicolumn{2}{|c|}{ Comparison } & \multirow{2}{*}{$\begin{array}{c}\mathrm{PE}(\%) \\
37.22\end{array}$} & \multicolumn{2}{|c|}{$90 \%$ CI (\%) } & \multirow{2}{*}{$\frac{\mathrm{CV}_{\text {ANOVA }}(\%)}{44.50}$} & \multirow{2}{*}{$\begin{array}{c}\text { Power (\%) } \\
54.13\end{array}$} \\
\hline INTRANASAL* & INTRAVENOUS & & 30.15 & 45.94 & & \\
\hline INTRANASAL* & TRANSMUCOSAL & 105.97 & 94.47 & 118.88 & 23.50 & 94.00 \\
\hline TRANSMUCOSAL & INTRAVENOUS & 35.12 & 28.06 & 43.96 & 47.70 & 49.72 \\
\hline TRANSMUCOSAL* & INTRAVENOUS & 8.78 & 7.02 & 10.99 & 45.60 & 49.72 \\
\hline INTRANASAL & TRANSMUCOSAL ${ }^{* *}$ & 463.88 & 424.64 & 506.73 & 17.90 & 94.00 \\
\hline
\end{tabular}

${ }^{*}$ Dose adjusted to $50 \mu \mathrm{g}$ fentanyl. ${ }^{* *}$ dose adjusted to $47 \mu \mathrm{g}$ fentanyl. $\mathrm{AUC}_{0 \text {-tlast }}$ area under the plasma concentration versus time curve from dosing time to the last measurement time point with concentration value above the lower limit of quantitation; $C_{\text {max }}$ : maximum concentration in plasma; PE: parametric point estimate; CI: confidence interval; CV\%: coefficient of variation.

TABLE 8: Summary of adverse events.

\begin{tabular}{|c|c|c|c|c|c|c|c|c|c|c|}
\hline & \multicolumn{2}{|c|}{ Total } & \multicolumn{2}{|c|}{ Naltrexone } & \multicolumn{2}{|c|}{ INTRANASAL } & \multicolumn{2}{|c|}{ INTRAVENOUS } & \multicolumn{2}{|c|}{ TRANSMUCOSAL } \\
\hline & Absolute & $\begin{array}{l}\text { Relative } \\
(\%)\end{array}$ & Absolute & $\begin{array}{l}\text { Relative } \\
(\%)\end{array}$ & Absolute & $\begin{array}{c}\text { Relative } \\
(\%)\end{array}$ & Absolute & $\begin{array}{c}\text { Relative } \\
(\%)\end{array}$ & Absolute & $\begin{array}{c}\text { Relative } \\
(\%)\end{array}$ \\
\hline $\begin{array}{l}\text { Adverse events } \\
\text { (AEs) }\end{array}$ & 38 & 100 & & & & & & & & \\
\hline $\begin{array}{l}\text { Volunteers without } \\
\text { AEs }\end{array}$ & 10 & 37 & & & & & & & & \\
\hline $\begin{array}{l}\text { Volunteers with } \\
\text { AEs }\end{array}$ & 17 & 63 & & & & & & & & \\
\hline \multicolumn{11}{|l|}{ Maximum intensity } \\
\hline Mild & 31 & 82 & 3 & 60 & 11 & 79 & 12 & 100 & 5 & 71 \\
\hline Moderate & 7 & 18 & 2 & 40 & 3 & 21 & 0 & 0 & 2 & 29 \\
\hline Severe & 0 & 0 & 0 & 0 & 0 & 0 & 0 & 0 & 0 & 0 \\
\hline \multicolumn{11}{|l|}{ Drug relationship } \\
\hline Probable & 0 & 0 & 0 & 0 & 0 & 0 & 0 & 0 & 0 & 0 \\
\hline Possible & 14 & 37 & 0 & 0 & 7 & 50 & 3 & 25 & 4 & 57 \\
\hline $\begin{array}{l}\text { No causal } \\
\text { relationship }\end{array}$ & 11 & 29 & 3 & 60 & 2 & 14 & 5 & 42 & 1 & 14 \\
\hline Unclassified & 13 & 34 & 2 & 40 & 5 & 36 & 4 & 33 & 2 & 29 \\
\hline \multicolumn{11}{|l|}{ Outcome } \\
\hline Recovered & 38 & 100 & 5 & 100 & 14 & 100 & 12 & 100 & 7 & 100 \\
\hline $\begin{array}{l}\text { Recovered with } \\
\text { sequelae }\end{array}$ & 0 & 0 & 0 & 0 & 0 & 0 & 0 & 0 & 0 & 0 \\
\hline Not yet recovered & 0 & 0 & 0 & 0 & 0 & 0 & 0 & 0 & 0 & 0 \\
\hline Death & 0 & 0 & 0 & 0 & 0 & 0 & 0 & 0 & 0 & 0 \\
\hline Unknown & 0 & 0 & 0 & 0 & 0 & 0 & 0 & 0 & 0 & 0 \\
\hline \multicolumn{11}{|l|}{ Seriousness } \\
\hline Serious & 0 & 0 & 0 & 0 & 0 & 0 & 0 & 0 & 0 & 0 \\
\hline Not serious & 38 & 100 & 5 & 100 & 14 & 100 & 12 & 100 & 7 & 100 \\
\hline \multicolumn{11}{|c|}{ Frequency of top 5 AEs } \\
\hline Headache & 5 & 13 & 0 & 0 & 2 & 14 & 1 & 8 & 2 & 29 \\
\hline Nausea & 7 & 18 & 0 & 0 & 1 & 7 & 4 & 33 & 2 & 29 \\
\hline Vomiting & 3 & 8 & 1 & 20 & 2 & 14 & 0 & 0 & 0 & 0 \\
\hline Tiredness & 2 & 5 & 0 & 0 & 2 & 14 & 0 & 0 & 0 & 0 \\
\hline Abdominal pain & 2 & 5 & 0 & 0 & 1 & 7 & 1 & 8 & 0 & 0 \\
\hline
\end{tabular}

are occasionally highly variable between subjects for certain fentanyl formulations $[34,35]$. In the case of the administration of intravenous fentanyl, a swift distribution into vascularised compartments and subsequently redistribution to fat and muscle tissue occur, while intranasal or oral administrated fentanyl is first distributed to local membranes before entering the systemic circulation [36]. Oral transmucosal absorption involves various factors such as the amount of salvia and has been described as complex [30]. The pharmacokinetic profile highly depends on the fraction absorbed by the oral mucosa, where around $25 \%$ of the available fentanyl is quickly absorbed and enters directly into circulation. The remaining fraction swallowed enters circulation later, but thereof around $50 \%$ is purged by enterohepatic and intestinal first-pass elimination [37]. This can also be noticed by the depicted biphasic pharmacokinetic profile for TRANSMUCOSAL. Individual constitution of the entire 
body and individual metabolism have therefore a considerable influence on the parameters. It cannot be assured that even in the same volunteer the characteristics of absorption and distribution of fentanyl remain comparable on the various different study days [30]. The variability of such values of intranasal fentanyl appears to be lower than other routes of administration; however, the importance of such variations of pharmacokinetic properties for clinical practice has apparently only a minor effect on efficacy or tolerability [38].

INTRANASAL exhibits only half the extent of exposure $\left(\mathrm{AUC}_{0 \text {-tlast }}\right)$ compared with TRANSMUCOSAL, which contains four times more fentanyl. Relative bioavailability after dose adjustment is estimated to be considerably lower for TRANSMUCOSAL. In conjunction with other parameters, comparable $C_{\max }$ values may serve as an indication that INTRANASAL and TRANSMUCOSAL might result in comparable clinical efficacy for acute pain.

$C_{\text {max }}$ point estimates for INTRANASAL are considerably higher when compared to dose-adjusted TRANSMUCOSAL. Intranasal administration delivers the drug first to the central blood compartment before it can cross the blood-brain barrier. This is supported by the nasal mucosa, which exhibits comparatively high blood circulation, even higher than the issue of the liver or muscles, and, as such, circumvents first-pass metabolism [39]. Also, the nasal administration route partly delivers the molecule directly to the site of action of the CNS [40]. Therefore, the intranasal administration of lower doses of opioids may potentially lead to similar therapeutic effects compared to other modes of administration [41]. In addition, the blunted peak exposure compared to intravenous fentanyl may also be favourable from a safety perspective.

INTRANASAL reached maximum concentrations $\left(t_{\max }\right)$ in a shorter timeframe than TRANSMUCOSAL, confirming results from a previous study [17], although it still took more than three times longer to reach $t_{\max }$ compared with the intravenous investigational product. Excluding intravenous injection, intranasal administration of fentanyl is the fastest noninvasive administration route to reach $t_{\max }$ before lozenges, sublingual tablets and sprays, buccal tablets, and films, as well as transdermal delivery systems $[18,42]$. The finding suggests and confirms that intranasal administration is principally beneficial for rapid acute pain relief.

Striebel et al. carried out various studies to assess the suitability of intranasal fentanyl for postoperative pain management $[16,24,43,44]$. For these investigations, the team used the intravenous formulation of fentanyl $(50 \mu \mathrm{g} /$ $\mathrm{mL}$ ) administered intranasally in six puffs of $90 \mu \mathrm{L}$ each dose, totalling $27 \mu \mathrm{g}$ fentanyl in $0.54 \mathrm{~mL}(0.27 \mathrm{~mL}$ per nostril). In one randomised, double-blind study, the efficacy of intranasal versus intravenous demand-adapted titration (repeated dosing every five minutes until no longer required or requested) was tested in a standardised population of 42 patients with intense pain after surgery for lumbar intervertebral disk protrusion [43]. All patients were satisfied with the pain reduction achieved. The same treatment schedule was used in another study, but an unselected population of 112 patients with severe postoperative pain was assessed herein [44]. Adequate pain relief was achieved in 52 of 53 patients of the intranasal cohort and in all patients in the intravenous group.

The formulation investigated within this study contains $47 \mu \mathrm{g}$ of fentanyl per administration, and the bioavailability was determined in the magnitude of $77 \%$ (unadjusted), leading to around $36 \mu \mathrm{g}$ fentanyl being systemically available. Such an amount of systemically available fenantyl would exceed the amount of fentanyl patients received in the aforementioned Striebel studies. Therefore, the chosen concentration of $47 \mu \mathrm{g}$ fentanyl for intranasal administration appears sufficient for adequate postoperative pain relief.

\section{Conclusion}

Presented data strongly affirm the assumption that the developed and investigated intranasal formulation is principally suitable for intranasal PCA.

\section{Data Availability}

The data used to support the findings of this study are available from the corresponding author upon request and approval by the rights owner.

\section{Conflicts of Interest}

SNH and LE are co-inventors of the aforementioned intranasal PCA device under development. The other co-authors do not have anything to declare.

\section{Acknowledgments}

This study was funded by Haupt Pharma Wolfratshausen $\mathrm{GmbH}$, Germany.

\section{References}

[1] T. H. Stanley, "The history and development of the fentanyl series," Journal of Pain and Symptom Management, vol. 7, no. 3, pp. S3-S7, 1992.

[2] L. E. Mather, "Clinical pharmacokinetics of fentanyl and its newer derivatives," Clinical Pharmacokinetics, vol. 8, no. 5, pp. 422-446, 1983.

[3] T. Tateishi, Y. Krivoruk, Y.-F. Ueng, A. J. J. Wood, F. P. Guengerich, and M. Wood, "Identification of human liver cytochrome P-450 3A4 as the enzyme responsible for fentanyl and sufentanil N-dealkylation," Anesthesia \& Analgesia, vol. 82, no. 1, pp. 167-172, 1996.

[4] R. B. Labroo, M. F. Paine, K. E. Thummel, and E. D. Kharasch, "Fentanyl metabolism by human hepatic and intestinal cytochrome P450 3A4: implications for interindividual variability in disposition, efficacy, and drug interactions," Drug Metabolism and Disposition: The Biological Fate of Chemicals, vol. 25, pp. 1072-1080, 1997.

[5] T. Goromaru, H. Matsuura, N. Yoshimura et al., "Identification and quantitative determination of fentanyl metabolites in patients by gas chromatography-mass spectrometry," Anesthesiology, vol. 61, no. 1, pp. 73-77, 1984.

[6] H. S. Smith, "Opioid metabolism," Mayo Clinic Proceedings, vol. 84, no. 7, pp. 613-624, 2009. 
[7] V. C. Ziesenitz, S. K. König, N. S. Mahlke, G. Skopp, W. E. Haefeli, and G. Mikus, "Pharmacokinetic interaction of intravenous fentanyl with ketoconazole," The Journal of Clinical Pharmacology, vol. 55, no. 6, pp. 708-717, 2015.

[8] P. Armenian, K. T. Vo, J. Barr-Walker, and K. L. Lynch, "Fentanyl, fentanyl analogs and novel synthetic opioids: a comprehensive review," Neuropharmacology, vol. 134, pp. 121-132, 2018.

[9] I. Panagiotou and K. Mystakidou, "Intranasal fentanyl: from pharmacokinetics and bioavailability to current treatment applications," Expert Review of Anticancer Therapy, vol. 10, no. 7, pp. 1009-1021, 2010.

[10] E. R. Viscusi, L. Reynolds, S. Tait, T. Melson, and L. E. Atkinson, "An iontophoretic fentanyl patient-activated analgesic delivery system for postoperative pain: a doubleblind, placebo-controlled trial," Anesthesia \& Analgesia, vol. 102, no. 1, pp. 188-194, 2006.

[11] W. Jeal and P. Benfield, "Transdermal fentanyl," Drugs, vol. 53, no. 1, pp. 109-138, 1997.

[12] F. Elsner, G. Zeppetella, J. Porta-Sales, and I. Tagarro, "Newer generation fentanyl transmucosal products for breakthrough pain in opioid-tolerant cancer patients," Clinical Drug Investigation, vol. 31, no. 9, pp. 605-618, 2011.

[13] S. C. Lim, M. J. Paech, V. B. Sunderland, M. J. Roberts, S. L. Banks, and M. W. Rucklidge, "Pharmacokinetics of nasal fentanyl," Journal of Pharmacy Practice and Research, vol. 33, no. 1, pp. 59-64, 2003.

[14] P. Watts, A. Smith, and M. Perelman, "Nasal delivery of fentanyl," Drug Delivery and Translational Research, vol. 3, no. 1, pp. 75-83, 2013.

[15] D. Foster, R. Upton, L. Christrup, and L. Popper, "Pharmacokinetics and pharmacodynamics of intranasal versus intravenous fentanyl in patients with pain after oral surgery," The Annals of Pharmacotherapy, vol. 42, no. 10, pp. 13801387, 2008.

[16] H. W. Striebel, J. Krämer, I. Luhmann, I. Rohierse-Hohler, and A. Rieger, "Pharmakokinetische Studie zur intranasalen Gabe von Fentanyl," Schmerz, Der, vol. 7, no. 2, pp. 122-125, 1993.

[17] A. Fisher, M. Watling, A. Smith, and A. Knight, "Pharmacokinetics and relative bioavailability of fentanyl pectin nasal spray 100-800 $\mu \mathrm{g}$ in healthy volunteers," International Journal of Clinical Pharmacology and Therapeutics, vol. 48, no. 12, pp. 860-867, 2010.

[18] J. Lötsch, C. Walter, M. J. Parnham, B. G. Oertel, and G. Geisslinger, "Pharmacokinetics of non-intravenous formulations of fentanyl," Clinical Pharmacokinetics, vol. 52, pp. 23-36, 2013.

[19] E. D. McNicol, M. C. Ferguson, and J. Hudcova, "Patient controlled opioid analgesia versus non-patient controlled opioid analgesia for postoperative pain," in The Cochrane Collaboration, John Wiley \& Sons, Ltd, Chichester, UK, 2015.

[20] S. Nardi-Hiebl, T. Meuser, G. Geldner, J. Schneider, T. Koch, and L. H. Chappell Eberhart, "Quo vadis OPS 8-919? Eine Analyse der Kodierungen und die Bedeutung für den klinischen Alltag," Pain Therapy, vol. 62, pp. 146-156, 2021.

[21] L. Eberhart, S. Nardi-Hiebl, N. Kubitz, T. Koch, S. Grond, and H. Schreder, "Prozesskostenanalyse in der postoperativen Schmerztherapie-vergleich der iv PCA mit einem nichtinvasiven, iontophoretischen, patientenaktivierten, transdermalen System (iPATS)," Anästhesiologie \& Intensivmedizin, vol. 50, p. 677, 2009.

[22] M. D. Thomas Meuser, Ms Stefan Nardi-Hiebl, M. D. Leopold Eberhart, M. D. Matthias Paul, R. Böttger, and M. D. Jörg Reutershan, "Staff time requirements for postoperative pain management: comparison of sufentanil sublingual tablet system and intravenous patient-controlled analgesia," Journal of Opioid Management, vol. 16, pp. 33-39, 2020.

[23] M. Jove, D. W. Griffin, H. S. Minkowitz, B. Ben-David, M. A. Evashenk, and P. P. Palmer, "Sufentanil sublingual tablet system for the management of postoperative pain after knee or hip arthroplasty," Anesthesiology, vol. 123, no. 2, pp. 434-443, 2015.

[24] H. W. Striebel, T. Olmann, C. Spies, and G. Brummer, "Patient-controlled intranasal analgesia (PCINA) for the management of postoperative pain: a pilot study," Journal of Clinical Anesthesia, vol. 8, no. 1, pp. 4-8, 1996.

[25] S. Toussaint, J. Maidl, R. Schwagmeier, and H. W. Striebel, "Patient-controlled intranasal analgesia: effective alternative to intravenous PCA for postoperative pain relief," Canadian Journal of Anesthesia/Journal canadien d'anesthésie, vol. 47, no. 4, pp. 299-302, 2000.

[26] R. Schwagmeier, T. Oelmann, T. Dannappel, and H. W. Striebel, "Patientenakzeptanz gegenber der patientenkontrollierten intranasalen Analgesie (PCINA)," Anaesthesist, Der, vol. 45, no. 3, pp. 231-234, 1996.

[27] L. Eberhart, I. Jackl, and S. Nardi-Hiebl, Nasal Applicator, US9033939B2, 2015.

[28] State Chamber of Physicians of Thuringia. Germany. Reference ZIE/1045/06/111. Protocol registration number 05ct148fe n.d.

[29] European Union Drug Regulating Authorities Clinical Trials Database. Nr. 003034-17 n.d.

[30] J. B. Streisand, M. A. Busch, T. D. Egan, B. G. Smith, M. Gay, and N. L. Pace, "Dose proportionality and pharmacokinetics of oral transmucosal fentanyl citrate," Anesthesiology, vol. 88, no. 2, pp. 305-309, 1998.

[31] N. M. L. Veldhorst-Janssen, A. A. A. Fiddelers, P.-H. M. van der Kuy et al., "Pharmacokinetics, analgesic effect, and tolerability of a single preprocedural dose of intranasal fentanyl in patients undergoing drain removal after breast reduction or augmentation surgery: a prospective, randomized, double-blind, placebo-controlled study," Clinical Therapeutics, vol. 32, no. 7, pp. 1427-1436, 2010.

[32] S. Kaasa, K. Moksnes, T. Nolte, D. Lefebvre-Kuntz, L. Popper, and H. G. Kress, "Pharmacokinetics of intranasal fentanyl spray in patients with cancer and breakthrough pain," Journal of opioid management, vol. 6, pp. 17-26, 2010.

[33] K. Moksnes, O. M. Fredheim, P. Klepstad et al., "Early pharmacokinetics of nasal fentanyl: is there a significant arterio-venous difference?" European Journal of Clinical Pharmacology, vol. 64, no. 5, pp. 497-502, 2008.

[34] D. J. R. Duthie, A. D. McLaren, and W. S. Nimmo, "Pharmacokinetics of fentanyl during constant rate I.V. infusion for the relief of pain after surgery," British Journal of Anaesthesia, vol. 58, no. 9, pp. 950-956, 1986.

[35] D. A. McClain and C. C. Hug Jr, "Intravenous fentanyl kinetics," Clinical Pharmacology \& Therapeutics, vol. 28, no. 1, pp. 106-114, 1980.

[36] E. J. M. Kuip, M. L. Zandvliet, S. L. W. Koolen, R. H. J. Mathijssen, and C. C. D. van der Rijt, "A review of factors explaining variability in fentanyl pharmacokinetics; focus on implications for cancer patients," British Journal of Clinical Pharmacology, vol. 83, no. 2, pp. 294-313, 2017.

[37] K. Mystakidou, E. Katsouda, E. Parpa, L. Vlahos, and M. L. Tsiatas, "Oral transmucosal fentanyl citrate: overview of pharmacological and clinical characteristics," Drug Delivery, vol. 13, no. 4, pp. 269-276, 2006. 
[38] R. Janknegt, M. van den Beuken, S. Schiere et al., "Rapid acting fentanyl formulations in breakthrough pain in cancer. Drug selection by means of the System of Objectified Judgement Analysis," The European Journal of Hospital Pharmacy: Science and Practice, vol. 25, p. e2, 2018.

[39] M. Paech and K. Shelley, "The clinical applications of intranasal opioids," Current Drug Delivery, vol. 5, no. 1, pp. 55-58, 2008.

[40] S. V. Dhuria, L. R. Hanson, and W. H. Frey, "Intranasal delivery to the central nervous system: mechanisms and experimental considerations," Journal of Pharmaceutical Sciences, vol. 99, no. 4, pp. 1654-1673, 2010.

[41] T. Vyas, A. Shahiwala, S. Marathe, and A. Misra, "Intranasal drug delivery for brain targeting," Current Drug Delivery, vol. 2, no. 2, pp. 165-175, 2005.

[42] H. S. Minkowitz, "A review of sufentanil and the sufentanil sublingual tablet system for acute moderate to severe pain," Pain Management, vol. 5, no. 4, pp. 237-250, 2015.

[43] H. W. Striebel, D. Koenigs, and J. Krämer, "Postoperative pain management by intranasal demand-adapted fentanyl titration," Anesthesiology, vol. 77, no. 2, pp. 281-285, 1992.

[44] H. W. Striebel, J. Pommerening, and A. Rieger, "Intranasal fentanyl titration for postoperative pain management in an unselected population," Anaesthesia, vol. 48, no. 9, pp. 753-757, 1993. 